Maxime Moulard Elmostafa Bahraoui

\title{
Rôle de la maturation protéolytique des glycoprotéines d'enveloppe virale
}

Les glycoprotéines des enveloppes virales proviennent généralement d'un précurseur clivé par une endoprotéase cellulaire ubiquitaire. Les précurseurs sont activés par protéolyse au niveau d'une séquence consensus du type (Arg/Lys)-X* -(Arg/Lys)-Arg. Ce motif est également représenté au niveau du site de clivage des pro-protéines. Les enzymes responsables de la maturation des précurseurs de protéines cellulaires commencent à être mieux connues. Certaines d'entre elles sont capables de protéolyser correctement les glycoprotéines d'enveloppe virale. L'inhibition de l'étape de maturation entraîne la formation d'un virus non infectieux. De ce fait, l'étude des mécanismes cellulaires d'activation par protéolyse des précurseurs des glycoprotéines d'enveloppe constitue un enjeu important, notamment au plan thérapeutique. Actuellement, plusieurs types d'inhibiteurs sont testés, qui pourraient se révéler précieux pour le traitement des maladies virales.

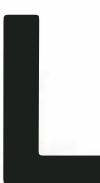

e clivage endoprotéolytique des protéines membranaires et des protéines sécrétées est une modification post-traductionnelle fréquente dans la voie d'exocytose ; il a lieu généralement après une arginine. Parmi ces pro-protéines, on trouve aussi bien des précurseurs d'hormones peptidiques, des neuropeptides, des facteurs de croissance, des protéines de la cascade de coagulation, des protéines circulantes (sérum albumine), des récepteurs membranaires et des molécules d'adhérence (figure 1) [1].
Ces protéines jouent des rôles très variés dans les processus biologiques et leurs fonctions ne s'expriment qu'à la condition que les précurseurs correspondants soient activés par clivage endoprotéolytique. Ce type de maturation a également été mis en évidence pour l'activation de nombreuses protéines membranaires virales et rétrovirales. En général, il apparaît là encore que le clivage des précurseurs doit avoir lieu pour l'expression de l'activité biologique du virus.

* X représente $n$ imporle quel acide aminé. 


\section{RÉFÉRENCES}

1. Barr PJ. Mammalian subtilisins : the long sought dibasic processing endoproteases. Cell 1991; $66: 1-3$.

2. Homma M, Ohuchi M. Trypsin action on the growth of Sendai virus in tissue culture cells. Structural difference of Sendai viruses grown in eggs and tissue culture cells. J Virol $1973 ; 12: 1457-65$.

3. Glickman RI, Sydall RJ, Iorio RM, Sheehan JP, Bratt MA. Quantitative basic residue requirements in the cleavage-activation site of the fusion glycoprotein as a determinant of virulence for Newcastle disease virus. $J V_{i-}$ rol $1988 ; 62$ : 354-6.

4. Klenk HD, Rott R, Ohrlich M, Blodorn J. Activation of influenza $A$ viruses by trypsin treatment. Virology $1975 ; 68: 426-39$.

5. Vey M, Orlich M, Adler S, Klenk HD, Rott R, Garten W. Hemagglutinin activation of pathogenic avian influenza viruses of seroty-
pe $H 7$ requires the protease recognition motif R-X-R/R-R. Virology $1992 ; 188$ : 408 13

6. Deshpande KI, Fried VA, Ando M, Webster RG. Glycosylation affects cleavage of an $\mathrm{H} 5 \mathrm{~N} 2$ influenza virus hemagglutinin and regulates virulence. Pror Natl Acad Sri USA $9987: 84: 36-40$.

7. McCune JM, Rabin I.B, Feinberg MB, el al. Endoproteolytic cleavage of $\mathrm{gp} 160$ is required for the activation of human immunodeficiency virus. Cell $1988 ; 53: 55-67$.

8. Freed EO, Risser R. The role of the HIV envelope glycoproteins in cell fusion and the pathogenicity of AIDS. Bull Inst Pasteur $1990 ; 88: 73-110$.

9. Bosh V, Pawlita M. Mutational analysis of the human immunodeficiency virus type 1 env gene product proteolytic cleavage site. I Virol $1990 ; 64: 2337-44$

10. Fenouillet E. La N-glycosylation du VIH: du modèle expérimental à l'application thérapeutique. médecine/sriences $1993 ; 9: 901-6$.

11. Fenouillet E, Gluckman JC; Jones IM. Functions of HIV envelope glycans. Trends Biochem Sci 1994 ; 19 : 65-70.

12. Benjouad A, Fenouillet E. Réponse immune contre les glycoprotéines d'enveloppe du virus de l'immunodéficience humaine : la glycosylation, bouclier ou talon d'Achille? médecine/sciences $1994 ; 10$ : 54450

13. Gotoh B, Ogasawara T, Toyoda T, Inocencio NM, Homaguchi M, Nagai Y. An endoprotease homologous to the blood clotting factor $X$ as a determinant of viral tropism in chick embryo. $E M B O / 1990 ; 9$ :
Relations entre le pouvoir pathogène viral et l'activation des glycoprotéines d'enveloppe

Les glycoprotéines de l'enveloppe des virus et des rétrovirus font apparaitre plusieurs similitudes strictes. Elles proviennent d'un précurseur de haut poids moléculaire qui est clivé par une endoprotéase de la cellule hôte. Après clivage, l'extrémité N-terminale du précurseur est extramembranaire et la partie (-terminale, qui contient une séquence hydrophobe, est ancrée dans la membrane virale. Les glycoprotéines d'enveloppe sont largement glycosylées (structures high mannose) au cours du transport jusqu'à la membrane plasmique cel-

\section{Protéines d'enveloppe virale}

$\begin{array}{lll}\text { HIV }-1 & \text { V } & \text { V } \\ \text { HIV-2 } & \text { A } & \text { P } \\ \text { SIV } & \text { G } & \text { T } \\ \text { RSV } & \text { T } & \text { G } \\ \text { HTLV-1 } & \text { L } & \text { G } \\ \text { FeLV } & \text { K } & \text { A } \\ \text { MuLV } & \text { R } & \text { S } \\ \text { \% rabies V } & \text { V } & \text { A } \\ \text { hFV } & \text { N } & \text { N } \\ \text { hCMV } & \text { T } & \text { H } \\ \text { FPV } & \text { S } & \text { K } \\ \text { MMTV } & \text { N } & \text { L }\end{array}$

$\begin{array}{ll} & -4 \\ Q & R \\ T & K \\ S & R \\ \text { I } & R \\ S & R \\ \text { V } & R \\ N & R \\ \text { R } & R \\ \text { K } & R \\ \text { N } & R \\ \text { K } & R \\ \text { l } & R\end{array}$

\begin{tabular}{ccc}
\multicolumn{3}{c}{ Site de clivage $\downarrow$} \\
-3 & -2 & -1 \\
E & K & R \\
E & K & R \\
N & K & R \\
R & K & R \\
S & R & R \\
F & R & R \\
H & K & R \\
A & R & R \\
K & R & R \\
T & K & R \\
E & K & R \\
A & K & R
\end{tabular}

\section{Récepteurs}

$\begin{array}{lllllllllll}\text { Lipop. R } & \text { T } & \text { S } & \text { N } & \text { R } & \text { H } & \text { R } & \text { R } & \text { Q } & \text { I }\end{array}$

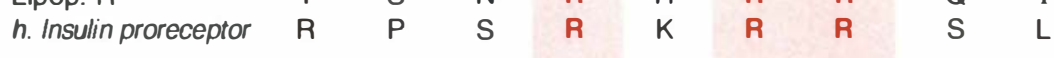

\section{Protéines plasmatiques}

\begin{tabular}{|c|c|c|c|c|c|c|c|c|}
\hline h. pro-protéine C & V & $\mathrm{L}$ & $\mathrm{R}$ & 1 & $\mathrm{R}$ & $\mathbf{K}$ & $\mathbf{R}$ & A \\
\hline h. pro-albumine & & $\mathrm{R}$ & G & V & $\mathrm{F}$ & $\mathbf{R}$ & $\mathbf{R}$ & $\mathrm{D}$ \\
\hline h. pro-C3 & $\mathrm{P}$ & A & $A$ & $\mathbf{R}$ & $\mathrm{R}$ & $\mathbf{R}$ & $\mathbf{R}$ & $\mathrm{S}$ \\
\hline bov. pro-F. X & V & $\mathrm{L}$ & $\mathrm{Q}$ & $\mathbf{R}$ & A & $\mathbf{R}$ & $\mathbf{R}$ & A \\
\hline h. pro-insuline & Y & $\mathrm{T}$ & $\mathrm{P}$ & $\mathbf{K}$ & $\mathrm{T}$ & $\mathbf{R}$ & $\mathbf{R}$ & A \\
\hline \multicolumn{9}{|l|}{ Hormones } \\
\hline h. pro-PTH & $\mathrm{S}$ & $L$ & $\mathrm{R}$ & $\mathbf{R}$ & $\mathrm{L}$ & $\mathbf{K}$ & $\mathbf{R}$ & A \\
\hline pro-somatostatine & $M$ & A & $P$ & $\mathbf{R}$ & $E$ & $\mathbf{K}$ & $\mathbf{R}$ & A \\
\hline pro-ocytocine & C & $P$ & $\mathrm{~L}$ & G & G & $\mathbf{K}$ & $\mathbf{R}$ & A \\
\hline
\end{tabular}

Figure 1. Comparaison des sites de clivage des pro-protéines, pro-hormones, pro-récepteurs et précurseurs des glycoprotéines d'enveloppe virale et rétrovirale. Les sites de maturation protéolytique reconnus par les endoprotéases cellulaires sont toujours constitués par au moins un doublet d'acides aminés basiques Lys-Arg ou Arg-Arg en position - 2 et -1 du site de clivage et comprend souvent un acide aminé basique Arg ou Lys en position - 4. Les résidus basiques sont en rouge. HIV : human immunodeficiency viruses ; SIV: simian immunodeficiency virus; HTLV-1 : human T-leukemia virus type $1 ; R S V$ : Rous sarcoma virus ; FeLV, feline leukemia virus ; MuLV : murine leukemia virus $; \psi$ rabies $V:$ pseudorabies virus ; $h F V$ : human foamy virus ; hCMV : human cytomegalovirus ; FPV : influenza virus ; MMTV : mouse mammary tumor virus. $h ;=$ humain ; bov. $;=$ bovin. Code à une lettre des acides aminés : $A: A l a ; C:$ Cys ; $D:$ Asp ; $E: G l u ; F: P h e ; G: G l y ; H$ : His ;

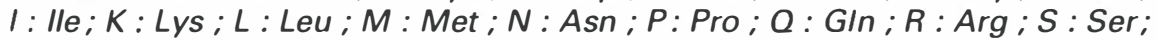
$T: T h r ; V: V a l ; W: T r p ; Y: T y r$. 
lulaire. Au niveau de l'appareil de Golgi, les chaînes glycosidiques sont élaguées, puis modifiées par l'adjonction de résidus d'acide sialique, de fucose, de galactose ou de N-acétyl glucosamine. Après clivage, les glycoprotéines restent associées ou non par l'intermédiaire de ponts disulfure et peuvent se polymériser sous la forme de dimère ou de multimère. L.e rôle de chacune de ces modifications post-traductionnelles est encore assez mal compris et fait l'objet d'intenses recherches. Cependant, l'inhibition d'une ou de plusieurs de ces étapes enzymatiques entraîne irrémédiablement, directement ou indirectement, la synthèse de glycoprotéine d'enveloppe non fonctionnelle, provoquant ainsi la formation d'un virus ayant perdu son pouvoir infectieux. L'activation protéolytique des précurseurs des glycoprotéines d'enveloppe virale par les protéases cellulaires est cruciale pour la réplication du virus. (ie phénomène a été mis en évidence pour la première fois sur la protéine F du virus de Sendai [2]. Le clivage du précurseur entraîne l'exposition d'une séquence hydrophobe très conservée, appelée peptide de fusion, à l'extrémité N-terminale du fragment Fl. Le peptide $\mathrm{N}$-terminal induit la fusion de la membrane virale avec la membrane plasmique de la cellule cible, permettant ainsi au génome viral de s'intégrer dans le cytoplasme cellulaire. I.e clivage de la protéine F est donc une étape nécessaire pour l'infectivité du virus.

De plus, l'activation d'un virus par clivage du précurseur de ses glycoprotéines d'enveloppe est un déterminant important pour le pouvoir pathogène du virus. Cela a été montré dans le cas du virus de Newcastle (NDV) pour lequel plusieurs souches connues présentent une virulence variable. Les protéines $\mathrm{F}$ des enveloppes virales des souches virulentes et avirulentes diffère dans sa sensibilité au clivage par les enzymes de maturation (figure 2). Pour les souches virulentes du NDV, la protéine F est clivée par une endoprotéase ubiquitaire, présente dans toutes les cellules analysées. A l'opposé, la protéine $\mathrm{F}$ des souches avirulentes n'est clivée que par des protéases représentées seulement dans quelques systèmes hôtes (cellules épithéliales du tractus digestif et des voies respiratoires).
Dans ce demier cas, l'infection ne dépasse pas le premier cycle de réplication [3] et ne cause que des infections très localisées.

De nombreuses études réalisées sur le clivage de l'hémagglutinine (HA) du virus influenza ont permis de montrer que des paramètres structuraux influent directement sur la sensibilité des précurseurs à la maturation protéolytique. Comme cela est le cas pour le virus de Sendai, le clivage de la glycoprotéine HA est essentiel pour permettre l'entrée du virus dans la cellule hôte, la dissémination de l'infection à travers l'organisme et l'expression du pouvoir pathogène du virus [4]. Chez les mammifères, les souches virales non pathogènes des virus influenza expriment à leur surface des précurseurs HA qui ne sont généralement clivés que dans un nombre restreint de types cellulaires, conduisant à des infections localisées. Inversement, des souches aviaires pathogènes possèdent des précurseurs HA qui sont activés par un grand nombre de types cellulaires différents, causant ainsi une infection systémique.

L'analyse au niveau moléculaire de la séquence du site de clivage des hémagglutinines de souches non pathogènes fait apparaître un site monobasique constitué d'une arginine (figure 2). En revanche, dans le cas des virus aviaires, la séquence du site de clivage est toujours composée d'un enchaînement polybasique d'acides aminés (figure 2). Ces observations, faites à partir de différentes souches naturelles du virus influenza, ont permis de formuler l'hypothèse selon laquelle il existerait une relation entre la capacité d'un virus à infecter des cellules hôtes et la sensibilité au clivage des précurseurs des glycoprotéines d'enveloppe. Par la suite, des mutations effectuées au niveau du site de clivage du précurseur HA, créées par mutagenèse dirigée, ont permis de vérifier cette hypothèse [5]. De cette analyse, a été déduit un site consensus de clivage du type Arg-X-(Lys/Arg)-Arg [5].

En plus de la présence d'un tel site, d'autres paramètres peuvent influer sur la susceptibilité au clivage. Par exemple, la présence ou non d'un site de glycosylation au voisinage du site de clivage interfère avec l'accessibilité de la protéase cellulaire. Ainsi, la perte d'un site de glycosylation sur l'hémagglutinine conduit à une augmentation du clivage de la glycoprotéine HA de la souche aviaire du virus influenza (A/Chick/Pen/83 H5N2) [6].

\section{Cas de la gp160 du VIH-1}

L.e gène env du VIH-l code pour un précurseur (gpl60) de 160 kDa qui est clivé par une endoprotéase cellulaire dans l'appareil de ('olgi au niveau de la séquence $\operatorname{Arg}^{5010}$-(ilu-L.ys$\operatorname{Arg}^{511}$ [7] pour engendrer la gpl20, qui constitue la sous-unité externe, responsable de l'interaction avec le récepteur CD4 des cellules cibles (lymphocytes T4/monocytes et macrophages), et la gp41, qui constitue la sous-unité transmembranaire, responsable de la fusion des membranes virales et cellulaires. I.es glycoprotéines gpl20 et gp4l, associées par des liaisons non covalentes, sont largement glycosylées (50\% de la masse moléculaire) et forment des oligomères. Les étapes de glycosylation et d'oligomérisation sont essentielles pour le transport et la maturation des glycoprotéines du virion [8]. La gpl 20 comprend des régions conservées $(\mathrm{Cl}$ à $\mathrm{C} .5)$ et des régions hypervariables (VI à V5) d'une souche à l'autre. En plus des régions conservées, il est remarquable de noter que la région du site de maturation protéolytique reste invariable sur les différentes souches virales caractérisées. Expérimentalement, les mutations ponctuelles éliminant partiellement ou totalement les acides aminés basiques du site de maturation (site 2) conduisent toujours à une diminution du taux de clivage de la gpl 60 et entraînent simultanément une perte du pouvoir infectieux se traduisant par une réduction de l'activité transcriptase inverse propre au virus et une diminution de la capacité de former in vitro des cellules géantes multinucléées ou syncylia (figure 3) [9]. Contrairement au virus influenza, aucune souche de VIH présentant un site de clivage défectueux n'a été isolée. Comme dans le cas de la glycoprotéine d'enveloppe du virus influenza, d'autres facteurs influent sur l'efficacité du clivage du précurseur gpl60. Certains inhibiteurs de la glycosylation ont des effets importants sur le clivage enzymatique de la gpl60 


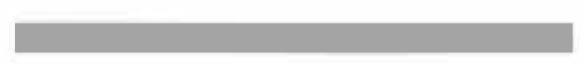

\section{RÉFÉRENCES}

14. Stieneke-Gröber A, Vey M, et al. Influenza virus hemagglutinin with multibasic cleavage site is activated by furin, a subtilisin-
like endoprotease. $E M B O J 1992 ; 11$ : 2407-14.

15. Moulard M, Montagnier L, Bahraoui E. Effects of calcium ions on proteolytic processing of HIV-1 gpl60 precursor and on cell fusion. FEBS Ielt 1994 ; 338 : 281-4.

16. Moulard M, Achstetter $\mathrm{T}$, Ikehara $\mathrm{Y}, \mathrm{Ba}$ rhaoui $\mathrm{E}$. T4-lymphocyte endoprotease responsible for the proteolytic processing of HIV-1 gpl60, like Kex2p endoprotease, is a calcium-dependent enzyme. Biochimie 1994 ; 76: 251-6.

17. Fuller RS, Brake A, Thomer J. Yeast prohormone-processing enzyme (KEX2 gene product) is a $\mathrm{Ca}^{2+}$-dependent serine protease. Proc Nall Acad Sci USA 1989 ; 86 : 1434-8.

18. Brenner $C_{4}$, Fuller RS. Structural and enzymatic characterization of a purified prohormone-processing enzyme: secreted, soluble KEX2 protease. Proc Nall Acad Sa USA $1992 ; 89: 922-6$.

19. Moulard M, Achstetter T, Montagnier I Kiény MP, Bahraoui E. Kex2p: a model for cellular endoprotease processing HIV-1 envelope glycoprotein precursor. Eur J Biochem 1994 ; 225 : $565-72$.

20. Misumi Y, Oda K, Fujiwara T, Takami N, Tashiro K, Ikehara Y. Functional expression of furin demonstrating its intracellular localization and endoprotease activity for processing of proalbumin and complement proC3.J Biol Chem 1991 ; 266 : 16954-9.

21. Wise RJ, Barr PJ, Wong PA, Kiefer MC, Brake AJ, Kaufman RJ. Expression of a human proprotein processing enzyme : correct cleavage of the von Willebrand factor precursor at a paired basic amino acid site. Proc Nall Acad Sci USA 1990 ; 87 : 9378-82.

22. Germain D, Zollinger L, Racine C, et al. The yeast KEX-2-processing endoprotease is active in the Golgi apparatus of transfected NIH 3T3 fibroblasts. Mol Endocrinol 1990 . $4: 1572-9$.

23. Stein BS, Engleman EG. Intracellular processing of the gpl60 HIV-1 envelope precursor. I Biol Chem 1990 ; 265 : 2640-9.

24. Hallenberger $S$, Bosch V, Angliker $H$, Shaw E, Klenk HD, Garten W. Inhibition of furin-mediated cleavage activation of HIV-1 glycoprotein gpl60. Nature $1992 ; 360$ : 35861.

25. Gotoh B, Ohnishi Y, Inocencio NM, $t$ al. Mammalian subtilisin-related proteinases in cleavage activation of the paramyxovirus fusion glycoprotein: superiority of furin/

PACE to PCi2 or PC1/PC3. J Virol 1992;66:

\begin{tabular}{|c|c|c|c|c|c|c|c|c|c|}
\hline \multicolumn{9}{|c|}{ Cite de livase I } & \\
\hline & & & & -4 & -3 & -2 & -1 & +1 & \\
\hline \multicolumn{10}{|c|}{ Souches virulentes } \\
\hline $\mathrm{FPV} / 34$ & & $\mathrm{~K}$ & $\mathrm{~K}$ & $\mathbf{R}$ & $E$ & $\mathbf{K}$ & $\mathbf{R}$ & $\mathrm{G}$ & \\
\hline Terr/SA/61 & & $T$ & $\mathrm{R}$ & $\mathbf{R}$ & $\mathrm{N}$ & $\mathbf{K}$ & $\mathbf{R}$ & $\mathrm{G}$ & \\
\hline Ty/lre 83 & & $\mathrm{R}$ & $\mathrm{K}$ & $\mathbf{R}$ & $\mathrm{K}$ & $\mathbf{K}$ & $\mathbf{R}$ & $\mathrm{G}$ & \\
\hline \multicolumn{10}{|c|}{ Souches avirulentes } \\
\hline Aichi/2/68(H3) & & & & K & $Q$ & $\mathrm{~T}$ & $\mathbf{R}$ & $\mathrm{G}$ & \\
\hline Avirulent $\mathrm{H} 5$ virus & & & & $\mathbf{R}$ & $E$ & $T$ & $\mathbf{R}$ & $\mathrm{G}$ & \\
\hline Avirulent $\mathrm{H} 7$ virus & & & & & $\bar{K}$ & $T$ & R & G & \\
\hline \multicolumn{10}{|l|}{ B } \\
\hline Virulent (AV) & $\mathrm{G}$ & $\mathrm{G}$ & $\mathrm{R}$ & $\mathbf{R}$ & $Q$ & $\mathbf{K}$ & $\mathbf{R}$ & $\mathrm{F}$ & 1 \\
\hline Virulent (AV) & G & G & $\mathrm{R}$ & $\mathbf{R}$ & $Q$ & $\mathbf{R}$ & $\mathbf{R}$ & $\mathrm{F}$ & 1 \\
\hline Virulent (AV) & $\mathrm{G}$ & $\mathrm{G}$ & $\mathrm{R}$ & $\mathbf{R}$ & $\bar{Q}$ & $\mathbf{R}$ & $\mathbf{R}$ & $\mathrm{F}$ & i \\
\hline Avirulent (N) & & & G & Bi & $Q$ & G & $\mathbf{R}$ & $\mathrm{L}$ & 1 \\
\hline Avirulent (B) & & & $\mathrm{G}$ & $\mathbf{R}$ & $\mathrm{Q}$ & $\mathrm{G}$ & $\mathbf{R}$ & $\mathrm{L}$ & 1 \\
\hline Avirulent (U) & & & $\mathrm{G}$ & $\mathrm{K}$ & $\bar{Q}$ & $\mathrm{G}$ & R & $\bar{L}$ & 1 \\
\hline
\end{tabular}

Figure 2. Comparaison des séquences des sites de clivage des glycoprotéines d'enveloppe des souches pathogènes et non pathogènes des virus influenza et NDV (Newcastle disease virus). Les séquences en acides aminés du site de clivage de l'hémagglutinine du virus influenza (A) et de la protéine $F$ du NDV (B) pour les souches virulentes et avirulentes sont alignées. La maturation a lieu après une paire d'acides aminés basiques Lys-Arg ou Arg-Arg. En l'absence du doublet, les précurseurs ne sont pas clivés et conduisent à la formation de virus non virulents.

[10]. Par exemple, des cellules infectées par le VIH-l et cultivées en présence de dNM (desoxynorijimycine) produisent un précurseur gpl60 très faiblement clivé par l'endoprotéase cellulaire [10-12]. Le virus produit dans ces conditions perd sa capacité de former des syncylic. Ces analogies permettent de penser que la maturation de la gpl60 suit la même voie que la maturation du précurseur HA du virus influenza.

\section{Protéases cellulaires impliquées dans le clivage}

Au niveau des sites monobasiques

L'activation protéolytique des glycoprotéines d'enveloppe virale des souches avirulentes a lieu au niveau d'un site de clivage spécifique, du côté C-terminal d'une arginine. Très récemment, les enzymes cellulaires responsables du clivage de ce type de précurseurs ont été identifiées au niveau moléculaire. Elles présentent des spécificités très variables en fonction de leurs substrats naturels et de leur distribution dans l’organisme. En général, ces glycoprotéines virales sont activées par des enzymes sécrétées par les cellules épithéliales. La plasmine est considérée comme activateur du précurseur HA de plusieurs souches du virus influenza. La VAP, pour virus aclivaling prolease, est une autre enzyme potentiellement impliquée dans les processus de maturation après une arginine. Isolée à partir de l'embryon de poulet, c'est une protéase à sérine, dépendante du calcium et composée de deux chaînes polypeptidiques. La première sous-unité $(33 \mathrm{kDa})$ comporte l'activité catalytique et la seconde (23 kDa) fixe le calcium. Enfin, elle présente une large homologie avec le facteur X [13]. Elle clive le précurseur HA du virus influenza et la protéine $F$ des paramyxovirus après l'arginine du site consensus de maturation (Gln/Glu)-X-Arg.

Au niveau des sites polybasiques

Les endoprotéases ubiquitaires responsables du clivage des précurseurs 


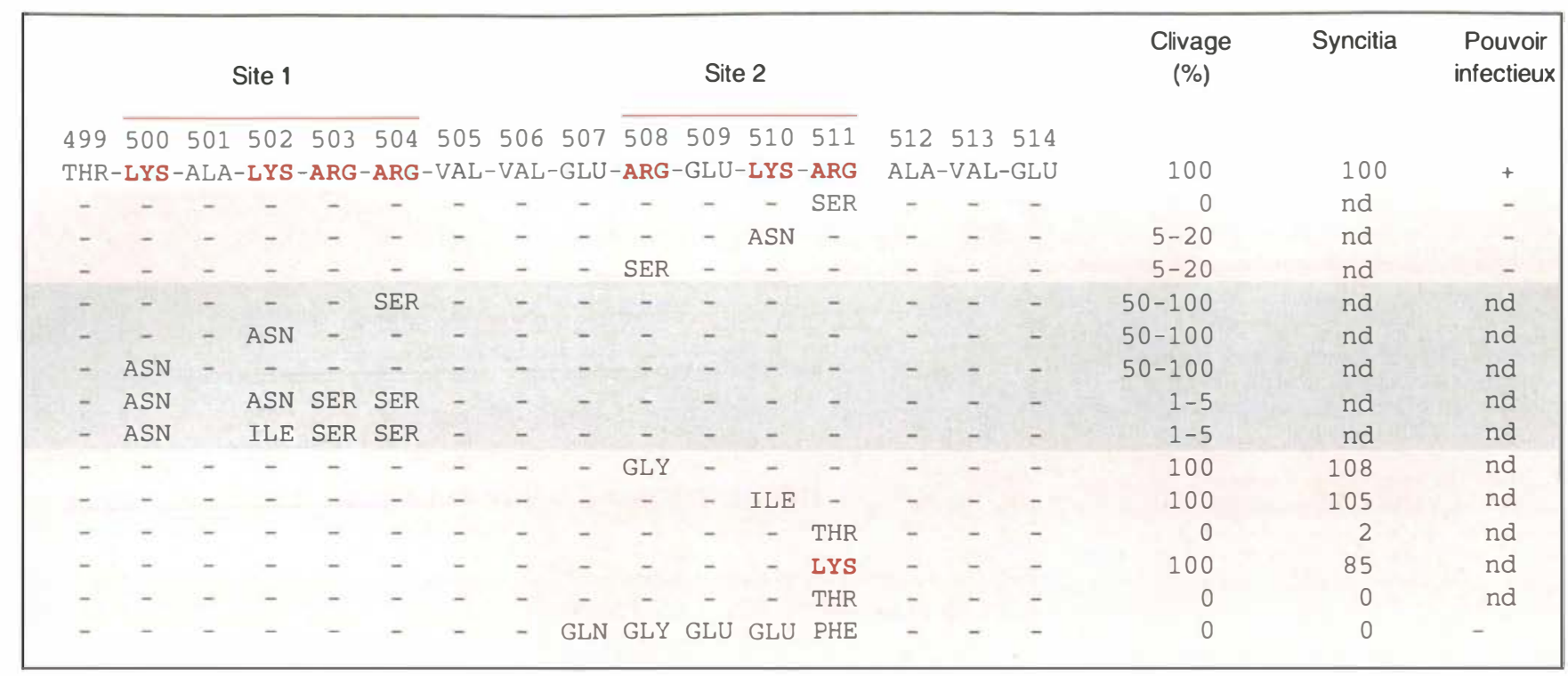

Figure 3. Mutations ponctuelles réalisées par mutagenèse dirigée au niveau des sites potentiels de clivage de la gp160 du HIV-1. Corrélation entre l'efficacité de clivage de la gp160 en gp120/gp41 de la souche HIV-1 BH10 et le pouvoir infectieux du virus produit. Alors que les mutations modifiant la nature du site 2 provoquent toujours la formation de virus non infectieux, celles affectant le site 1 ne modifient pas nécessairement le caractère infectieux du virus.

au niveau de séquences polybasiques constituées de plusieurs arginines et de lysines ne sont pas encore bien identifiées. En 1984, le groupe de Klenk a montré que la protéase intracellulaire responsable de la maturation du précurseur HA du FPV (fowl plaque virus) est une enzyme dépendante du calcium, ayant un $\mathrm{pH}$ optimum neutre [14], pouvant être inhibée par des dérivés peptidiques de type chloroalkylcétone [14]. De même, l'endoprotéase cellulaire responsable de la maturation de la gpl60) du VIH-1 est dépendante du calcium, comme l'ont montré les expériences de déplétion en ions calcium de la cellule infectée, à l'aide de l'ionophore A23187 [15, 16]. Ces enzymes semblent être très bien conservées puisque les précurseurs HA du FPV et gpl 60) du VIH-1 sont aussi bien activés dans toutes les cellules de mammifères testées que dans des cellules d'invertébrés.

Une enzyme ayant ce type de propriétés catalytiques et biochimiques a été découverte dans la levure Saccharomyces cerevisiae [17]. L'endoprotéase $\mathrm{m} / \mathrm{s} n^{\circ} 1$, vol. 11 , janvier 95
Kex $2 p$ coupe ses substrats naturels, pro- $\alpha$-factor et prokiller toxin, au niveau des doublets dibasiques Arg-Arg et Lys-Arg. In vitro, elle est capable de cliver correctement des prohormones de mammifère et des précurseurs de neuropeptides [18]. Enfin, la protéase Kex2p coupe la gpl60 du VIH-1 aussi bien in vitro que dans un système cellulaire [19]. La protéase Kex2p est donc considérée comme le prototype d'une nouvelle famille d'enzymes, les subtilisin-like endoprotéases, présentant des similarités structurales avec les subtilisines.

En ce qui concerne les endoprotéases cellulaires isolées, analogues à la Kex2p, le gène codant pour la furine a été cloné à partir de différents tissus aussi bien humains, que de mammifères ou de la drosophile. L'enzyme, qui possède une forte similitude de séquence primaire avec la protéase Kex2p au niveau du site actif, est présente dans la majorité des organes de ces espèces [20]. Sa présence, apparemment ubiquiste, suggère qu'elle est impliquée dans l'apprêtement des pro-protéines de la voie de l'exocytose constitutive [21]. Les observations biochimiques indiquent que le site de clivage de la furine doit contenir au moins une arginine en position -4, ainsi qu'une paire d'acides aminés basiques en position -2 et -1 . Cette condition met en évidence que les pro-protéines présentant un site d'activation tétrabasique Arg-(Lys/Arg)-Lys/Arg-Arg ou tribasique Arg-X-(Lys/Arg)-Arg sont potentiellement des substrats pour la furine [20]. Ces séquences consensus sont également retrouvées dans toutes les glycoprotéines d'enveloppe virale répertoriées (figure 1). De plus, la colocalisation subcellulaire de la furine [22] et du clivage de la majorité des précurseurs des glycoprotéines d'enveloppe [23] au niveau de l'appareil de Golgi, renforce l'hypothèse de l'intervention de la furine ou d'une endoprotéase homologue au cours de la maturation des précurseurs viraux.

A partir de ces observations, plusieurs groupes ont cherché à démontrer que la furine pourrait être un candidat potentiel pour la matura- 


\section{RÉFÉRENCES}

26. Ortmann D, Ohuchi M, Angliker $H$ Shaw E, Garten W, Klenk HD. Proteolytic cleavage of wild type and mutants of the $F$ protein of human parainfluenza virus type 3 by two subtilisin-like endoproteases, furin and Kex2. J Virol $1994 ; 68: 2772-6$.

27. Van de Ven WJM, Roebroek AJM, Van Duijnhoven HLP. Structure and function of eukaryotic proprotein processing enzymes of the subtilisin family of serine proteases Crit Rev Oncogenesis $1993 ; 4$ : 115-36.

28. Lusson J, Vieau D, Hamelin J, et al. cDNA structure of the mouse and rat subtilisin/kexin-like PC5. A candidate proprotein convertase expressed in endocrine and non endocrine cells. Proc Natl Acad Sci USA $1993 ; 90: 6691-5$.

29. Nakagawa T, Hosaka M, Torii S, Watanabe T, Murakami K, Nakayama K. Identification anf functional expression of a new member of the mammalian Kex2-like processing endoprotease family: its striking structural similarity to PACE4. I Biochem $1993 ; 113: 132-5$.

30. Thomas I, Leduc R, Thorne BA, Smeekens SP, Steiner DF, Thomas G. KEX'-like endoprotease $\mathrm{PC} 2$ and $\mathrm{PC} 3$ accurately cleave a model prohormone in mammalian cells : evidence for a common core of neuroendocrine processing enzymes. Proc Natl Acad Sci USA 1991 ; 88:5297-301.

31. Decroly E, Vandenbranden M, Ruysschaert JM, Cogniaux J, Jacob SJ, Howard SC, Marshall G, Kompelli A, Basak A, Jean F, Lazure C, Benjannet S, Chrétien M, Day $R$, Seidah NG. The convertases furin and PCI can both cleave the human immunodeficiency virus (HIV-1) envelope glycoprotein gpl 60 into gp 120 (HIV-1 SU) and gp4l (HIV-1 TM). J Biol Chem 1994 ; 269 : 12240 7.

32. Zhirnov OP, Ovcharenko AV, Bukrinskaya $A G$. Suppression of influenza virus replication in infected mice by protease inhibitors. J Gen Virol 1984; 65 : 191-6.

33. Anderson ED, Thomas L, Hayflick JS Thomas G. Inhibition of HIV-1 gp160-dependent membrane fusion by a furin-directed $\alpha_{1}$-antitrypsin variant. I Biol Chem 1993 ; $268: 24887-91$.

34. Kido H, Kamashita K, Fukutomi A, Katunuma N. Processing for gp 160 human immunodeficiency vitus type 1 envelope glycoprotein precursor in human $\mathrm{T4}+$ lymphocytes. / Biol Chem 1993 ; 268 : 1340613.

35. Ohnishi Y, Shioda T, Nakayama K, Iwata S, Gotoh B, Hamaguchi M, Nagai Y. A furindefective cell line is able to process correct-

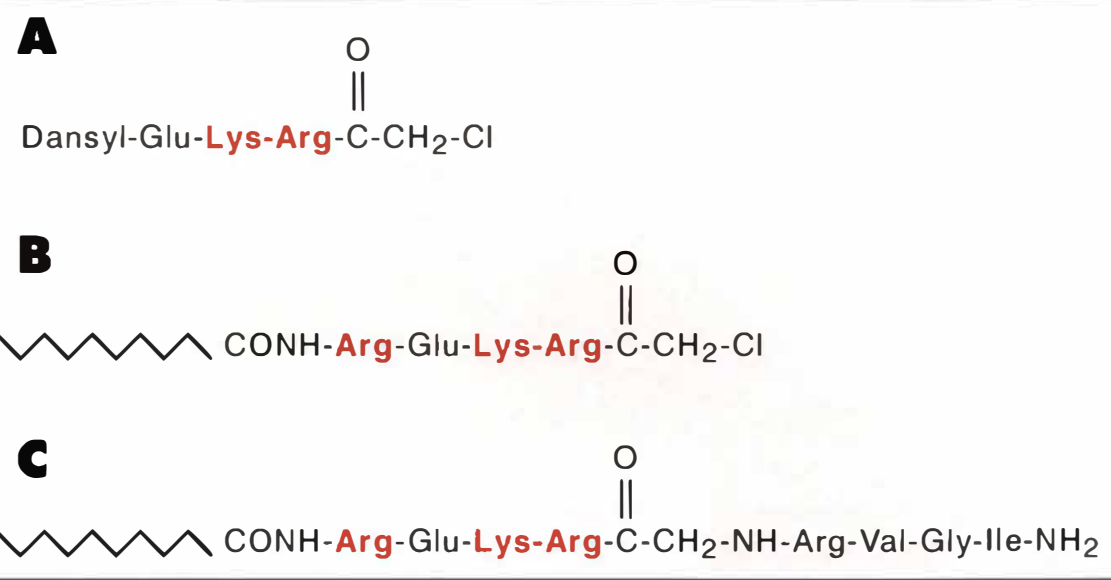

Figure 4. Structure des inhibiteurs synthétiques potentiels pour la maturation de la gp160 du HIV-1 et les précurseurs des glycoprotéines d'enveloppe des souches avirulentes des virus influenza, Sendai et NDV. 10 à 100 nM de l'inhibiteur A bloquent la maturation des précurseurs activés par la VAP (virus activating protease) potentiellement impliquée dans le clivage des précurseurs au niveau d'un site monobasique. Les dérivés chloroalkylcétones (B) et les pseudopeptides (C) sont respectivement des inhibiteurs irréversibles et réversibles des subtilisin-like endoprotéases. Un acide gras est branché en position $\mathrm{N}$-terminale des peptides pour favoriser le passage de la membrane plasmique de la cellule. Le clivage de la gp160 par la furine est inhibé à $100 \%$ lorsque la maturation est réalisée en présence des dérivés chloroalkylcétones $(50 \mu \mathrm{M})$ dans les cellules CV1 exprimant la gp 160 et la furine à l'aide des virus de la vaccine recombinants. In vitro, en présence des pseudopeptides $(50 \mu \mathrm{M})$, le clivage de la gp160 par l'endoprotéase PC1 est inhibé à $72 \%$.

tion des précurseurs viraux. La première glycoprotéine virale qui s'est avérée clivée par la furine a été le précurseur HA du virus influenza. Cette observation résulte de deux approches différentes : l'hémagglutinine du FPV est correctement clivée lorsqu'elle est co-exprimée avec la furine humaine ; la furine bovine, purifiée à partir d'une lignée cellulaire de foie (cellules MDBK, souche permettant la réplication in vivo du virus FPV), s'avère être la protéase responsable du clivage de l'HA [14]. De la même façon, la furine clive correctement le précurseur gpl 60) du VIH-1 [24], la protéine F d'une souche pathogène du virus NDV [25], et la protéine F du para-influenza virus de type III [26].

Le nombre d'endoprotéases appartenant à la famille des subtilisin-like protéases s'accroît rapidement, incluant les enzymes PCl ou PC3*, PC2, PC4,
PACE4** [27], et enfin PC.5 [28] et PC6 [29]. Les protéases $\mathrm{PCl} / 3$ et PC2, exprimées uniquement dans les cellules neuroendocrines, sont probablement responsables de l'activation des prohormones au niveau des sites dibasiques Lys-Arg ou Arg-Arg [30]. Ce sont certainement des protéases solubles, présentes dans les vésicules de sécrétion ; elles font donc partie de la machinerie de la voie sécrétoire régulée [30]. De plus, l'activité spécifique de ces enzymes a été testée sur les protéines $F$ des souches pathogènes et non pathogènes du virus NDV mais, ni la séquence consensus $\operatorname{Arg-X-(Lys/Arg)-Arg~de~la~souche~}$ pathogène, ni la séquence ne comprenant qu'une seule arginine de la

\footnotetext{
* $P C=$ prohormones converases.

**PACE: = paired basic amino acid cleaving enzy-
} me. 
souche non pathogène, ne sont clivées par ces enzymes [25]. En revanche, l'endoprotéase $\mathrm{PC}: 1$ recombinante est parfaitement capable, in vitro, d'activer la gpl60 du VIH-l [31]. Le rôle possible que pourraient avoir ces endoprotéases dans la maturation des précurseurs des glycoprotéines d'enveloppe virale reste encore largement inexploré. Il n'est donc pas exclu que plusieurs protéases soient directement impliquées dans ces processus de maturation, cet événement dépendant du virus considéré et du type cellulaire infecté. Enfin, la fonction et la spécificité des protéases PAC.E4, PC.4 et P(.5 ne sont pas encore connues.

\section{Inhibition de l'activation des précurseurs}

\section{Inhibiteurs de synthèse}

Plusieurs inhibiteurs synthétiques de protéases bloquent l'activation des glycoprotéines d'enveloppe virale et sont ainsi capables de stopper la propagation du virus.

Pour les souches avirulentes des virus influenza, Sendai et NDV, activées par clivage après une arginine, la maturation peut être bloquée par l'aprotinine, l'acide $\varepsilon$-amino- $n$-caproïque ou par des dérivés chlorométhylcétones (figure 4).

- I'acide $\varepsilon$-amino-n-caproïque (analogue de la lysine) et l'aprotinine, respectivement inhibiteurs de la plasmine et des protéases à sérine (plasmine, kallikréine, trypsine et chymotrypsine), sont efficaces pour arrêter la dissémination et stopper la réplication du virus. La diminution observée de l'infection peut être due, soit à l'inhibition de l'activation de la plasmine, soit à l'inhibition de la plasmine elle-même. L'injection d'aprotinine ou d'acide $\varepsilon$-amino- $n$-caproïque, toutes les sixheures pendant sixjours, aux souris infectées par le virus influenza (souches $\mathrm{A} / \mathrm{PR} / 8 / 34$ (H0N1), A/Aichi/2/68 (H3N2) ou WSN), anéantit totalement la production virale. Des traitements aussi efficaces ont été obtenus chez le poulet, mais également au cours d'une étude clinique chez l'enfant. Dans les deux cas, ces inhibiteurs affectent la réplication des virus qui sont activés par des endoprotéases sécrétées [32].
- In vitro et in ovo, les dérivés chloroalkylcétones (figure 4) bloquent également la maturation par la VAP des précurseurs des glycoprotéines de souches avirulentes des virus influenza, Sendai et NDV [25]. Cependant, ces derniers inhibiteurs sont rapidement métabolisés après administration.

Des dérivés chloroalkylcétones de peptides contenant le motif Arg-X(Lys/Arg)-Arg ou des composés présentant une liaison pseudopeptidique au niveau du site de clivage (figure 4) sont des inhibiteurs potentiels de la protéase intracellulaire du type de la furine. Au même titre que les dérivés TPC.K et TL.CK inhibent la trypsine et la chymotrypsine, les dérivés chloroalkylcétones forment une liaison covalente avec la sérine du centre actif de la furine l'inactivant de façon irréversible. De tels composés inhibent l'activation protéolytique de l'hémagglutinine du virus influenza et bloquent ainsi la réplication du virus [14]. Ces mêmes inhibiteurs exercent une action similaire sur la maturation de la gpl60 du VIH-1, activée par la furine dans les cellules humaines [24]. En interférant avec le clivage de la gpl60, ces inhibiteurs réduisent la dissémination du virus et ont donc le potentiel d'arrêter la diffusion du virus. In vitro, les inhibiteurs possédant une liaison pseudopeptidique inhibent la maturation de la gpl60 par l'endoprotéase $\mathrm{PC}: \mathrm{l}$, mais s'avèrent incapables de bloquer la maturation du précurseur dans les cellules infectées. I.a toxicité et la faible proportion d'inhibiteur entrant dans la cellule rendent difficile l'utilisation de ces composés. C'es molécules constituent la première génération d'inhibiteurs, car ils présentent les inconvénients d'être difficiles à synthétiser, instables en milieu aqueux et de demeurer relativement toxiques au niveau cellulaire. Le développement et la recherche de nouveaux inhibiteurs, mais également l'étude du mode de transfert de ces molécules à travers la membrane plasmique, constituent un enjeu essentiel pour les prochaines années.

Inhibiteurs issus du génie moléculaire

L' $\alpha_{1}$-antitrypsine $\left(\alpha_{1}-\mathrm{AT}\right)$ humaine, protéine sérique de $55 \mathrm{kDa}$, est un in- hibiteur de l'élastase. Des mutations naturelles de l' $a_{1}$-AT dans le site réactif modifient la spécificité d'inhibition. Par exemple, dans le cas du variant Pittsburg de l' $\alpha_{1}$-antitrypsine ( $a_{1}$-AT.Pit), la méthionine 358 du site réactif qui est mutée en arginine confère à cet inhibiteur le pouvoir d'inhiber la thrombine et non plus l'élastase. Les malades affectés par cette anomalie génétique font des hémorragies mortelles.

Anderson et al. ont construit un mutant de l' $a_{1}$-AT dans lequel le site réactif naturel (Ala-Ile-Pro-Met ${ }^{358}$ ) a été changé en Arg-Ile-Pro-Arg. ${ }^{358}$. Le mutant comprend donc la séquence consensus minimale pour lui permettre une interaction avec la furine. Les auteurs ont montré que ce mutant est non seulement capable de bloquer la maturation du précurseur gpl60, mais aussi d'inhiber la formation de syncytia [33]. C'es résultats récents ouvrent une nouvelle voie utilisant la thérapie génique. Au niveau cellulaire, sous le contrôle d'un promoteur inductible par la présence du virus ou d'une protéine virale, le mutant pourrait être exprimé dans la cellule infectée, provoquant ainsi une réduction de l'activité de la furine et, par voie de conséquence, entraînerait la formation de particule virale non infectieuse.

\section{Conclusion}

Les glycoprotéines d'enveloppe virale proviennent d'un précurseur polyprotéique qui est protéolysé par une endoprotéase cellulaire au niveau d'une séquence consensus de type Arg-X-(Lys/Arg)-Arg. Des travaux récents ont permis de montrer que cette étape de maturation est absolument nécessaire pour l'acquisition du pouvoir infectieux du virus. Les résultats de McCiune et al. sur le VIH1 ont clairement montré, pour la première fois, que l'inhibition de l'étape de maturation de la gpl 60 en gpl 20 et gp4l entraîne la formation de particules virales non infectieuses [7].

Les expériences d'expression transitoire des enzymes présumées être du type Kex2p/furine dans différentes lignées cellulaires ont, en outre, montré que les précurseurs des glycoprotéines d'enveloppe virale sont correctement clivés par ces enzymes. 
Cependant, d'autres protéases pourraient être engagées dans cette étape de maturation. Par exemple, une protéase de $25 \mathrm{kDa}$ a été récemment isolée à partir d'une lignée lymphocytaire (cellules MOLT) [34]. Cette dernière enzyme présente des caractéristiques enzymatiques totalement différentes des subtilisin-like protéases citées ci-dessus et, en particulier, s'avère être indépendante du calcium. De plus, il a été récemment décrit qu'une lignée cellulaire humaine (LoVo), provenant du côlon, qui n'exprime pas la furine, est parfaitement capable de cliver correctement le précurseur gpl60 du VIH-1 [35]. En revanche, les cellules LoVo demeurent incapables d'activer le précurseur des glycoprotéines du virus NDV. Ces observations montrent que la furine n'est pas l'unique enzyme responsable de la maturation des précurseurs viraux. En conséquence, des efforts importants doivent être réalisés pour isoler ces enzymes et pour mieux comprendre leur rôle dans les mécanismes d'activation des pro-protéines, en général, et de la maturation des précurseurs des glycoprotéines d'enveloppe virale, en particulier. Enfin, l'étude de cette étape de maturation doit absolument être poursuivie dans le but de rechercher des inhibiteurs spécifiques, non toxiques, capables d'inhiber cette nouvelle classe d'enzymes $\left(m / s n^{\circ} 4\right.$, vol. 6, p. 399). Il devient de plus en plus clair que de tels inhibiteurs, qui auraient la capacité d'éradiquer aussi bien des virus à $\mathrm{ADN}$ que des rétrovirus, constituent une nouvelle classe de molécules présentant un intérêt thérapeutique évident

\section{Remerciements}

Ce travail a été rendu possible grâce aux soutiens successifs de l'ANRS, du CNRS, de l'Assistance publique de Marseille, de la FERS et de l'Inserm.

Ce travail est dédié à la mémoire de Victor Scarsi.

\section{TIRÉS À PART}

M. Moulard.

\section{Summary}

Role of proteolytic processing of viral envelope glycoproteins

Mature envelope glycoproteins of animal viruses and retroviruses are produced through the proteolytic processing of a precursor by an ubiquitous cellular endoprotease. Precursors were cleaved after a consensus motif consisting in (Arg/Lys)-X-(Arg/Lys)-Arg. These sequences are also usually presented in the cleavage site of exported pro-proteins. A few cellular enzymes responsible for the cleavage of pro-proteins were recently discovered and are under intensive investigations. Some of them activate precursors of viral envelope glycoproteins. Inhibition of this step leads to the formation of a non infectious virus. Many inhibitors have been designed and tested by different groups. Discovery of new molecules capable of blocking proteolytic processing of viral precursors will open new ways not only for basic research purposes but also for therapeutic treatment of viral and retroviral diseases. 